\title{
Assessing Water Demand of Green Roofs Under Variants of Climate Change Scenarios
}

\author{
Matteo Fiori, Tiziana Poli, Andrea G. Mainini, Juan Diego Blanco Cadena, \\ Alberto Speroni and Daniele Bocchiola
}

\begin{abstract}
Green roofs are a resource for the city: they mitigate pollution, decrease the urban heat island effect (UHI), and regulate storm runoff. Within a climate change scenario, green roofs might instead become an issue, and in particular, in mitigating UHI at mesoscale level. The aim of the contribution is to define the water balance and thus the water consumption of a typical green roof, considering its variation when immersed into different climate scenarios that took place in the past five years (Linked with the following research projects: (1) Research title: 2016, Fondazione Minoprio/Politecnico di Milano, Dipartimento ABC (ongoing), Research type: Convention, Responsible: Matteo Fiori. (2) Research title: 2018, Harpo Contract (ongoing), Research type: Funded by third parties, Responsible: Matteo Fiori. (3) Research title: 2018, Soprema Contract (ongoing), Research type: Funded by third parties, Responsible: Matteo Fiori. (4) Research title: 2018, ASSIMP T-dry Contract (ongoing), Research type: Funded by third parties, Responsible: Matteo Fiori).
\end{abstract}

Keywords Climate change $\cdot$ Green roof $\cdot$ Sustainable water management

\section{Green Roof Water Demand and Climate Change}

The content of water in green roofs affects the thermal performance of the roof surface layer, given the modified conductivity of the ground layer and the evaporative effect generated by the water state change. Green roofs have proven to be a good strategy for reducing the urban heat island effect, the storm water runoff in low water permeability surfaces areas, air pollutant concentrations, plus the reduction of solar gains from the roof exposure (Demuzere et al. 2014).

M. Fiori · T. Poli $(\bowtie)$ A A. G. Mainini · J. D. Blanco Cadena · A. Speroni Architecture, Built Environment and Construction Engineering-ABC Department, Politecnico di Milano, Milan, Italy

D. Bocchiola

Department of Civil and Environmental Engineering_-DICA, Politecnico di Milano, Milan, Italy

(C) The Author(s) 2020

S. Della Torre et al. (eds.), Regeneration of the Built Environment from a Circular Economy Perspective, Research for Development, https://doi.org/10.1007/978-3-030-33256-3_35 
Nevertheless, climate change is threatening the efficiency of these alternatives, given the strong heat stress, the large amplitude of the temperature variation to which the vegetation is exposed, and/or the increase of water vapor and decrease of liquid water in warm seasons (i.e., higher air's water vapor carrying capacity) (Wong et al. 2012). In consequence, some vegetation might not withstand the climate variations undergone at their location, modifying the thermal properties of the green roof (Paolini 2015). Fiori et al. (2013) and Simmons et al. (2008) have studied green roof performance for different green roof types, obtaining significant variance according to the combinations of soil, vegetation, and irrigation. Simmons et al. (2008) explored the variance of green roof maximum runoff retention and thermal properties at different water contents, for different green roofs' layer composition. Farrell et al. (2012) studied the survival of green roofs' vegetation when subjected to drought, testing their tolerance to limited irrigation, highlighting the importance of proper selection of the type of vegetation according to the climate.

Environmental alterations have been witnessed during the last five years (Wong et al. 2012); thus the way the green roof would respond for delivering the desired heat rejection. The research intends to show how the green roof has adapted to the variations in the temperature changes along the past decade and how these variances could be aided by the control of water content delivered to their vegetation and stored within the soil.

The following study has been presented and developed by SEEDLab.ABC, ABC Department, and Politecnico di Milano. All data has been surveyed thanks to the sensor installation done by METEOLab.ABC, and the data monitoring is carried out by SEEDLab.ABC. From the stored data, outdoor temperature, relative humidity (RH), total solar radiation, surface temperatures, and water content have been inspected for a green roof of a two-story office building in Milan, Italy $\left(45^{\circ} 28^{\prime} 47^{\prime \prime} \mathrm{N} ; 9^{\circ} 13^{\prime} 47^{\prime \prime} \mathrm{E}\right)$. The green roof is divided into eight parcels with different vegetation, plus a gravelfilled reference parcel, representing the original finishing of the roof. Each layer temperature has been surveyed to establish the heat transfer through them. A plan view of the green roof is shown in Fig. 1. The sensor distribution is described in the roof slab cross section as shown in Fig. 2. The data collected has been confronted to see how the local climate variances have affected the heat transfer.

\section{Weather and Green Roof Condition Variance}

All the data gathered has been condensed into three typical days for summer, midseason, and winter. From the average value encountered for the $24 \mathrm{~h}$ of June, March, and December, this was done for green roof parcels 5 (i.e., vegetation layer as sedum on moss) and 6 (i.e., vegetation layer as sedum on lapillus), during 2012, 2017, and 2018. Air temperature, relative humidity, and total solar radiation data, gathered from an on-site weather station, have been screened, together with the surface temperatures. Figure 3a shows how the fluctuation on solar radiation is high for March (i.e., $\sim 1.5$ times higher in 2012 than in 2018), but the air temperatures are approximately 


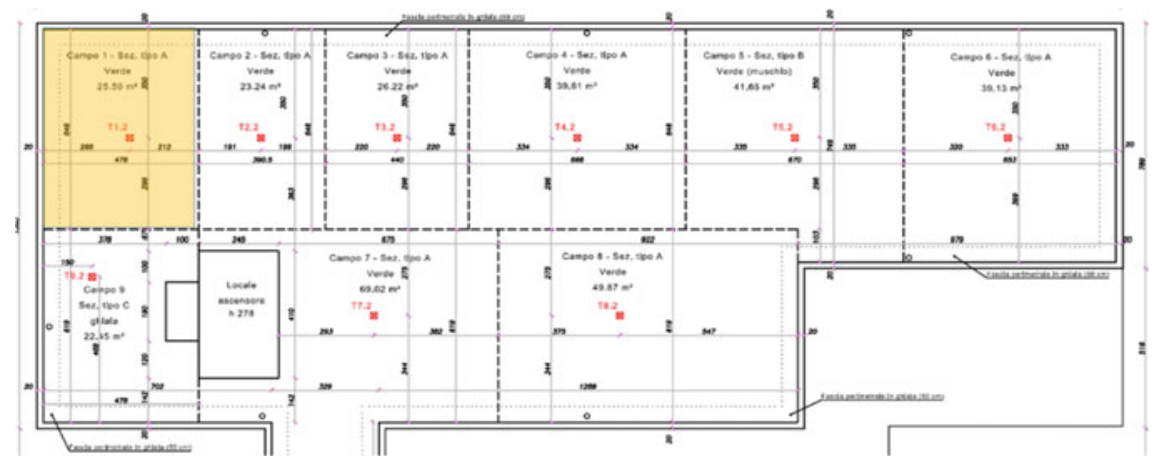

Fig. 1 Green roof plan view specifying sensor location. This work has concentrated on roof 5 and 6 (i.e., sedum on moss and sedum on lapillus). All dimensions are presented in $\mathrm{cm}$ by () SEEDLab.ABC, ABC Department, and Politecnico di Milano. Vegetation type is then described beside Fig. 2

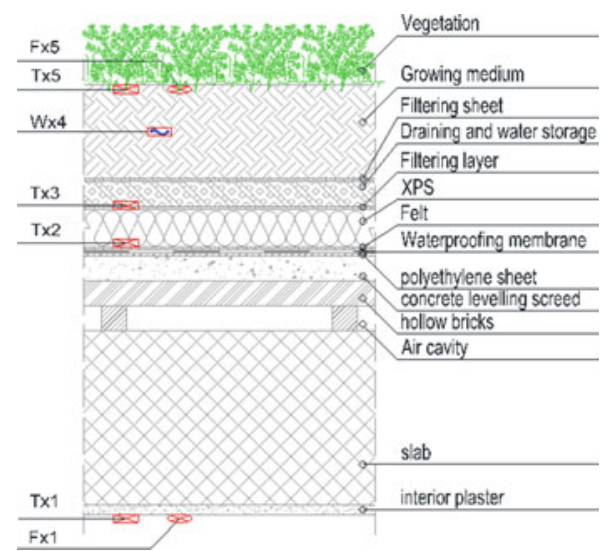

Fx\# : heat flux on parcel $x$ at position $\#\left[\mathrm{~W} / \mathrm{m}^{2}\right]$

Tx\# : temperature on parcel $x$ at position $\#\left[{ }^{\circ} \mathrm{C}\right]$

$\mathrm{Wx} \#$ : water content on parcel $x$ at position \# [\%]

Vegetation layer type:

- Small Bushes

(Parcel N.1)

- Aromatic plants

(Parcel N.2)

- Flowers and plants

(Parcel N.3)

- Flowering meadow

(Parcel N.4)

- Sedum on Moss

(Parcel N.5)

- Sedum on lapillus

(Parcel N.6)

- Common Grass

(Parcel N.7)

- Mediterranean Scrub (Parcel N.8)

- Gravel - Reference sample (Parcel N.9)

Fig. 2 Roof construction layer configuration, sensor location, and labeling. On the right, the description of the vegetation layer type for every parcel

similar for all three years (i.e., 2012, 2017, and 2018). Meanwhile, for air temperature during December, a difference of $\sim 2^{\circ}$ and $\sim 3^{\circ}$ was found from 2012 to 2017 and 2018, respectively (Fig. 3c), for a rather similar solar radiation exposure. The most significant behavior fluctuations can be seen for March and June (see Fig. 3a, b) for the heat flux F65, installed at greenery level on the exterior surface, monitored from 2012 to 2017 and the surface temperature T55 surveyed from 2012 to 2017 or 2018. Even at rather similar air temperatures and solar radiation average values, not only the amplitude of the hourly average during a day is significant (especially for the former) but also there is a notorious different trend (in particular, from T55-2012 to T55-2017 or 2018). This could be explained given the notorious difference on water 
(a)

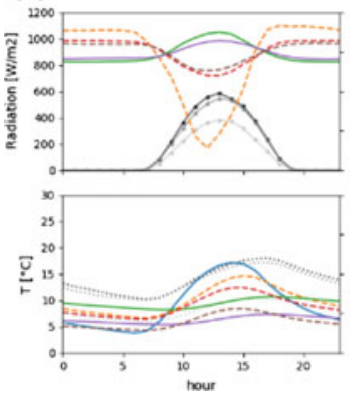

(b)

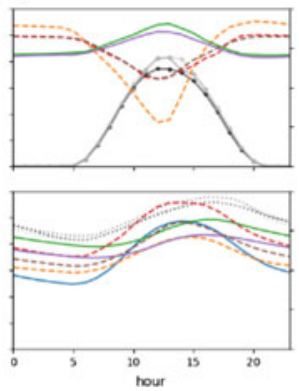

(c)

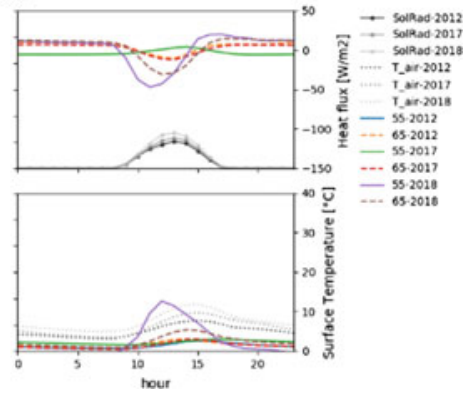

Fig. 3 Air and surface temperature, solar radiation, and heat transfer behavior $([+]$ toward environment, [-] toward room) for a typical day in a March (mid-season); b June (summer); c December (winter)

(a)
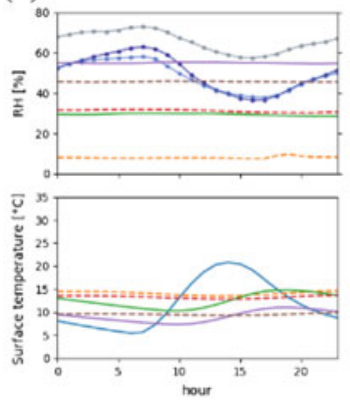

(b)
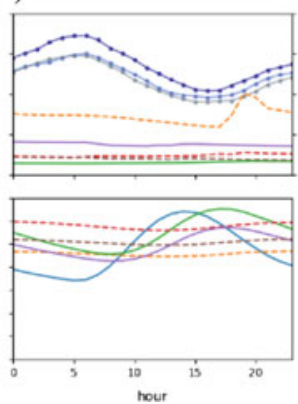

(c)
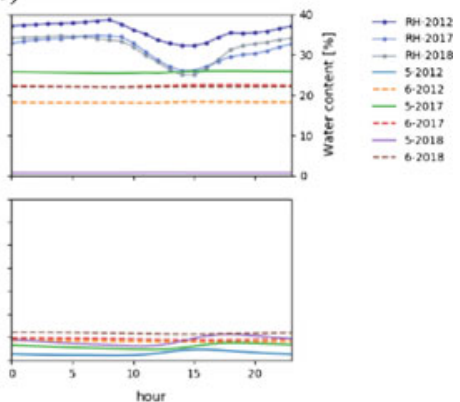

Fig. 4 Soil water content and external side of the insulation layer temperature behavior on a typical day for a March (mid-season); b June (summer); c December (winter)

content of the soil from 2012 to 2017 , that is from $\sim 4$ to $\sim 15 \%$ probably supplied throughout irrigation (hence, the similar values of RH; see Fig. 4a).

From Fig. 4, it can be concluded that most of the soil's water content was given by the water input transported through irrigation, as there can be seen almost no influence of the air's RH.

\section{Heat Influx Behavior Change}

As internal air temperatures are designed to fluctuate within a range, it is normal to find a moderately constant behavior of ceiling surface temperature as shown in Fig. 5. Only the visible oscillations go along the trend of the external air temperature.

On the other hand, the heat flux read by the sensor at the interior surface has a very particular behavior for March and December (see Fig. 5a, c), with a peak on 
(a)
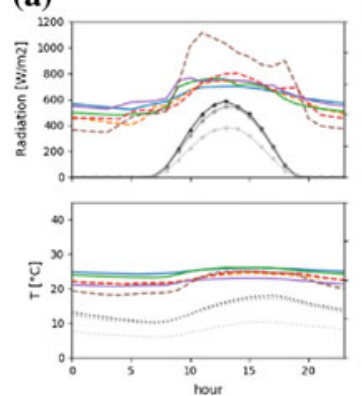

(b)

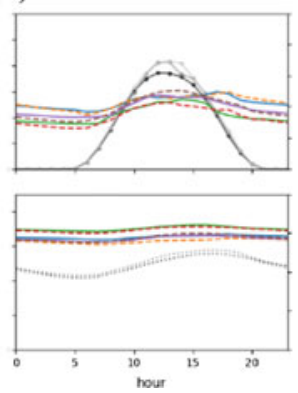

(c)

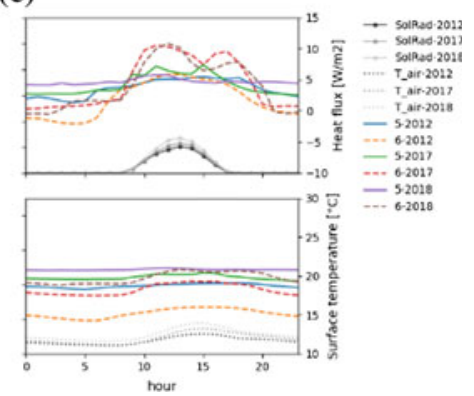

Fig. 5 Internal surface temperature and heat transfer behavior variance for a typical day in a March (mid-season); b June (summer); c December (winter)

the early occupancy hours and by the end of occupancy hours that correspond to the presence of internal heat gains combined with the most direct beam solar radiation entering the room beneath the roof surface. In 2018 and 2017, with a higher water content on the soil, it is noted that the heat flux from the interior to the exterior is larger; meanwhile, the heat coming from the exterior is lower.

It shall be noted as well how the two different types of vegetation (greenery and moss) on the green roofs behave in terms of inward heat flux, especially for March and June (see Fig. 3a, b). The green roof type 5 seems to have a greater water content retention (presents higher water content), thus, a lower peak amplitude, and it turns positive around midday. In contrast, green roof type 6 presents a much higher amplitude, in particular for March and June of $2012\left(>-90 \mathrm{~W} / \mathrm{m}^{2}\right)$ given its vegetation's high evaporative properties, and it is always on the opposite flux trajectory.

\section{Conclusions}

Green roofs are key passive strategies that bring great benefit in terms of sustainability to the urban scale and of energy savings to the local building scale. It must be noted that it is not a strategy that behaves equally throughout the year; it varies in accordance with the soil water content and the vegetation cover.

The significant variance of the green roof behavior at different water contents has been presented, and how climate fluctuations alter the green roof's thermal performance, requiring higher water input that determines different thermal conductivity values of the soil.

Further studies are foreseen to evaluate the water input required per each roof, maintaining a constant water content and how the roof's thermal performance varies throughout the year; measure roofs' vegetation proliferation and compare the thermal performance at normalized vegetation density conditions; and compare the aging 
effect on the roof's performance for green and cool roofs exposed to the same weathering conditions. Moreover, additional work is expected when more data is collected, that is after ten years of exposure and data collection, evaluating the presumed climate change effect on sustainable building passive strategies.

\section{References}

Demuzere, M., Orru, K., Heidrich, O., Olazabal, E., Geneletti, D., Orru, H., et al. (2014). Mitigating and adapting to climate change: Multi-functional and multi-scale assessment of green urban infrastructure. Journal of Environmental Management, 146, 107-115.

Farrell, C., Mitchell, R. E., Szota, C., Rayner, J. P., \& Williams, N. S. G. (2012). Green roofs for hot and dry climates: Interacting effects of plant water use, succulence and substrate. Ecological Engineering, 49, 270-276.

Fiori, M., Paolini, R., \& Poli, T. (2013). Monitoring of eight green roofs in Milano. Hygrothermal performance and microclimate mitigation potential. In 39th World Congress on Housing Science Changing Needs, Adaptive Buildings, Smart Cities (pp. 1365-1372). Milan, Italy: PoliScript, Milano.

Paolini, R. (2015). An overview on the performance over time of cool and green roofs as countermeasures to urban heat islands. Tema: Tempo, Materia, Architettura, 1(1), 9-14.

Simmons, M. T., Gardiner, B., Windhager, S., \& Tinsley, J. (2008). Green roofs are not created equal: The hydrologic and thermal performance of six different extensive green roofs and reflective and non-reflective roofs in a sub-tropical climate. Urban Ecosystems, 11(4), 339-348.

Wong, S. L., Wan, K. K. W., Yang, L., \& Lam, J. C. (2012). Changes in bioclimates in different climates around the world and implications for the built environment. Building and Environment, $57,214-222$.

Open Access This chapter is licensed under the terms of the Creative Commons Attribution 4.0 International License (http://creativecommons.org/licenses/by/4.0/), which permits use, sharing, adaptation, distribution and reproduction in any medium or format, as long as you give appropriate credit to the original author(s) and the source, provide a link to the Creative Commons license and indicate if changes were made.

The images or other third party material in this chapter are included in the chapter's Creative Commons license, unless indicated otherwise in a credit line to the material. If material is not included in the chapter's Creative Commons license and your intended use is not permitted by statutory regulation or exceeds the permitted use, you will need to obtain permission directly from the copyright holder.

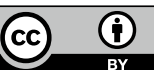

